\title{
Cryptosporidium and Its Public Health Importance: Review
}

\author{
Ahmed Mohammed; HailuDegefu; Kula Jilo \\ School of Veterinary Medicine, Jimma University, Jimma, Ethiopia \\ *Corresponding Author:Ahmed Mohammed, School of Veterinary Medicine, Jimma University, Jimma, \\ Ethiopia
}

\begin{abstract}
Summary: Cryptosporidiosis is the worldwide zoonotic disease caused by protozoan parasite of the genus Cryptosporidium which infects the micro-villous border of the gastrointestinal and respiratory epithelium of wide range of vertebrates including human beings and causing diarrhea in both immune-competent and immune-compromised individuals. It follows monoxenous life cycle which requires single host and grow only in living cells but can survive in the environment for long periods without losing its infectivity. Its transmission occurs through direct or indirect contact with feces of infected animals or humans whereas a contaminated food and water are source infection. Age, immune status, concurrent infection and resistance of the parasite to adverse environmental factors are the risk to factors associated with cryptosporidium infection. It's diagnosis of is mainly based on identification of oocysts from fecal materials while species identification rely on molecular techniques. Cryptosporidium causes high morbidity which results in production losses and death of live animals in the different countries of the world. Additionally, it accounts for up to $20 \%$ of all cases of childhood diarrhea in developing countries. Furthermore, it is a potentially fatal complication of AIDS. Since, it's highly resistance to antimicrobials and anticoccidials no effective therapeutic agent is available to date. Nevertheless, halofuginone lactate and nitazoxanide are being used for pro- and metaphylaxis treatment. As a result, good hygiene measures are important to control and prevent the disease. Moreover, comprehensive documented materials on cryptosporidium and its public health importance are scarce. Therefore, well compiled papers are needed for better understanding, effective treatment and implementation of sound prevention and control measures.
\end{abstract}

Keywords: Cryptosporidium, Protozoa, zoonotic, Parasite

\section{INTRODUCTION}

Cryptosporidiosis is the worldwide disease caused by protozoan parasite of the genus Cryptosporidium, which was discovered in 1910 by Edward Ernst Tyzzer in the gastric glands of mice and he named it from the Greece word "kruptos" meaning "hidden as it did not contain sporocysts within the oocysts and it sporulates while still attached to the host wall (Tyzzer, 1910). Cryptosporidium is an intracellular protozoan parasite that associated with gastrointestinal diseases with a wide host range affecting all classes of vertebrates including mammals, reptiles, birds and fish (Kosek et al, 2001; Chen et al., 2002). It is protected by an outer shell that allows it to survive outside the body for long periods of time and makes it very resistant to chlorine disinfectants (Kosek et al, 2001). As a result, the oocysts of the Cryptosporidium can survive for several months and retain infectivity in a latent form outside the host, despite adverse environmental factors, including salinity and chemicals (Sunnotel et al., 2006; Smith et al., 2007).

Cryptosporidium is monoxenous life cycle that causes diarrhea in immunocompromised individuals and neonates that believed as resulted from parasite invasion and epithelial destruction with the result of mild to moderate villus atrophy and microvillii shortening and destruction (deGraaf et al., 1999). Cryptosporidium oocysts are transmitted between hosts via the fecal-oral route, either directly from contact with faeces of infected animals or indirectly through environmental contamination or from ingestion of contaminated food or water whereas; age, immune status, concurrent infections, management and hygienic condition are the potential risk factors (Thomson, 2014). 
Diagnosis of cryptosporidiosis is traditionally based on the detection of fecal oocysts by fecal flotation but immunofluorescent assay visualization of oocysts is currently being used as diagnostic techniques in most clinical laboratories while Molecular technique like PCR required for species identification (Fayer and Xiao, 2008). Regarding its treatment, there is not guarantee for an effective treatment in both human and veterinary medicine. However; Nitazoxanide and Halofuginone are approved drugs for pro- and metaphylaxis treatment respectively (Shahiduzzaman and Daugschies, 2012).

Control of cryptosporidiosis has to rely on reducing the prevalence of the parasite and on breaking the transmission pathways of Cryptosporidium species causing disease in animals, transmitting them to humans (zoonotic) or those perpetuating infection in humans only (anthroponotic). However, such a documented information to initiate studies and planning of control measures is limited or totally absent in many countries of the world (Yosra, 2014). Similarly, in Ethiopia, despite it has been reported cryptosporidium infection is highly prevalent; there was scarcity of well documented information regarding economical and public health importance of this zoonotic parasite. Therefore, the objective of this review paper is:

- To review available information on cryptosporidium and its public health importance

\section{LITERATURE REVIEW}

\section{- Etiology and Taxonomy}

The taxonomic status of the genus Cryptosporidium remains enigmatic; the speciation of the genus continues to be a challenge to taxonomists. Traditionally, Cryptosporidia was considered as protozoan parasites due to great similarities and are classified in the Coccidia class of the phylum Apicomplex,although Cryptosporidia show features which differ them from all other Coccidia and concluded a closer affinity of Cryptosporidia with the gregarines (Apicomplexa: Gregarinasina) (Hijjawi et al., 2002). Similarly, Xiano et al.(2004), taxonomic studies place Cryptosporidium as a clade separate from the coccidian it invades the microvillus border of GIT and respiratory epithelium of a wide range of vertebrate animals and is associated with watery diarrhea in mammals, diarrhea and respiratory illness in birds and gastroenteritis in reptiles and fish. In addition, coccidian species are generally named based on unique oocyst morphology, but within the Cryptosporidium genus several species have similar oocyst morphology (Fayer, 2008). However, recent whole genome comparisons by Templeton et al. (2010), suggested that Cryptosporidium is neither coccidian nor gregarine. Therefore, Cryptosporidium may have its own separate lineage is likely to reveal new avenues of investigation into pathogenesis, epidemiology, treatment and control of these ubiquitous pathogens (Barta and Thompson, 2006).

\section{- Life Cycle of Cryptosporidium}

Cryptosporidium is a monoxenous organism, life cycle completed within a single host, which can be divided into an asexual (sporogony and schizogony/merogony) and a sexual (gamogony) phase (Fujino et al., 2002). The exogenous stage of the Cryptosporidium life cycle is a sporulated, thick walled oocyst which is excreted in the faeces of an infected host. However, the endogenous part of the life cycle begins when the infectious oocysts are ingested either via contaminated water or feed. In the gastrointestinal lumen the oocyst will release sporozoites, which parasitize the villous enterocytes. The developing stages remain at the luminal surface of the enterocytes. But they are covered by the plasma membrane of the host cell. Thus they are spoken of as being intracellular but extracytoplasmic. The sporozoites differentiate, intracellularly, into trophozoites (uninucleate meronts) that undergo asexual multiplication by nuclear division leaving behind type I and type II meronts. Type I meronts produce six to eight merozoites, which in turn invade epithelium cells and form type II meront. Type I merozoites can either go to a type II meront or return to form another generation of type I. The type II meront produces merozoites. They will initiate sexual multiplication as they differentiate into either male micro-gamonts or female macro-gamonts (Rimhanen-Finne, 2006). The fertilized macrogametes develop into thick walled oocyst, which are excreted from the body or into thin walled oocysts. The later is responsible for repeated asexual and sexual multiplication (autoinfection) within the same host (KHIN, 2007). 


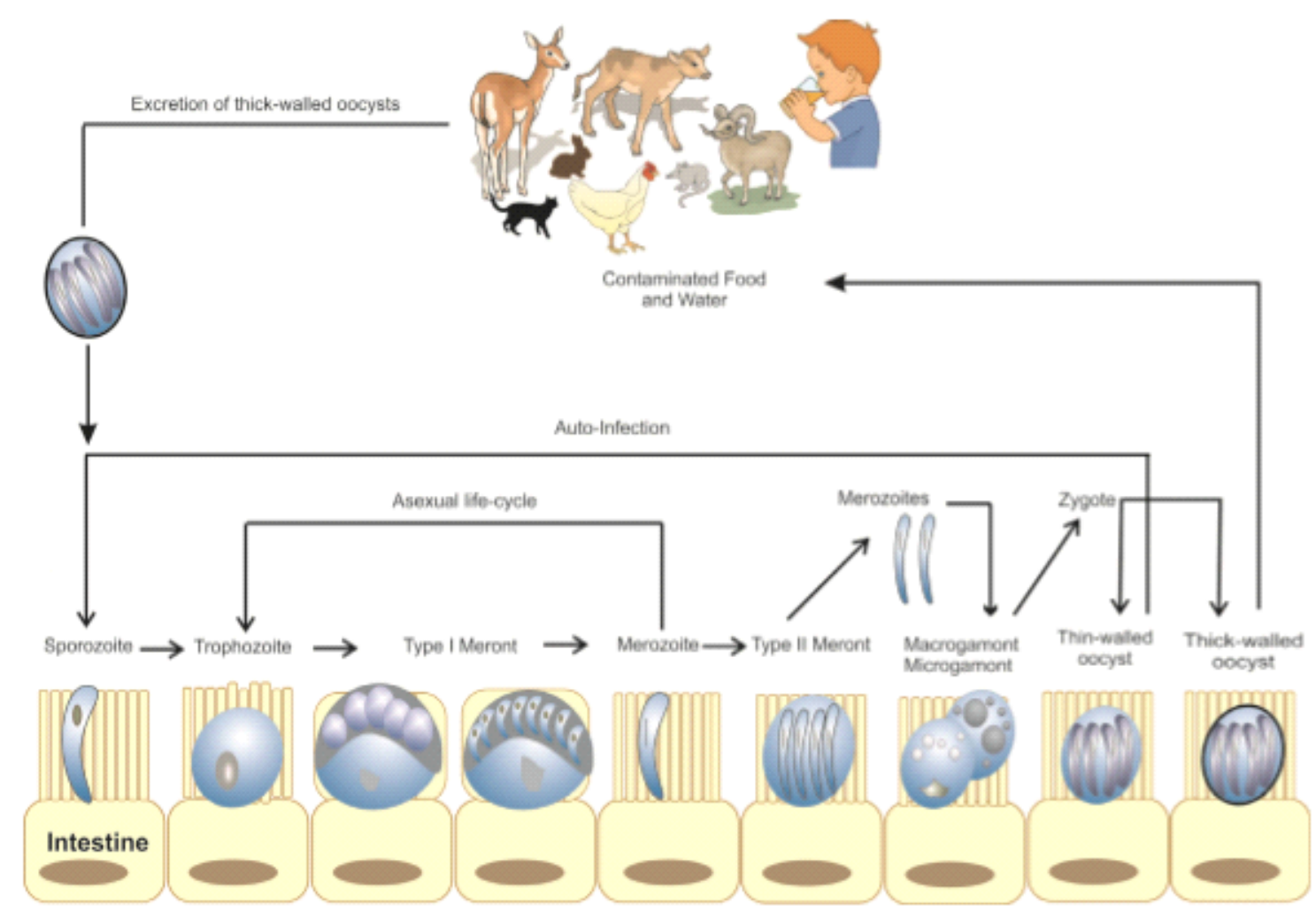

Source: (Yosra, 2014).

Figure 1.Life cycle of Cryptosporidium in different animal species and humans

The prepatent period in experimental or accidental infections with the different Cryptosporidium species varies from 2 to 14 days in various animal hosts and from 5 to 28 days in humans. The patent period in domestic and companion animals vary from one day to two to four weeks. Two morphological different species of Cryptosporidium are identified in cattle. The first, found in the small intestine, is $C$. parvum and the second, the stomach infecting larger species, are named $C$. andersoni (Lindsay et al., 2000). As the morphology, the molecular markers and the experimental infectivity of those two species vary, their prevalence also varies in relation to the age of the calves and to the housing technology (Santın et al., 2004). In addition to those dominant species multiple, less-closely related genotypes are also known. Some of these genotypes acquired a species name and many await further biological characterization (Xiao, 2004). Most recently, a species from cattle, $C$. bovis (formerly known as 'bovine B genotype'), and a 'deer-like genotype' are identified (Santin et $a l ., 2004)$. Both of these genotypes are biologically and genetically distinct from dominant species of C. hominis, C. parvum, bovine genotype and C. wrairi (Slapeta, 2007).

\section{- Epidemiology}

\section{- Geographical Distribution}

Cryptosporidiosis has been recognized worldwide, primarily in neonatal calves, but also in lambs, goat kids, foals, and piglets. Many studies report prevalence of infection but this does not imply clinical disease ((Radostits et al., 2006). In humans, the application of PCR assays to identify Cryptosporidium species from stool samples has shown that $C$. hominis and $C$. parvum are the major causes of human cryptosporidiosis (Cacciò, 2005). However; the prevalence of these species varies in different regions of the world. C. hominis is by far more prevalent in North and South America, Australia and Africa, while C. parvum causes more human infections in Europe, especially in the UK (Figure 2). Geographic variation occurs also within a country (McLauchlin et al., 2000) and molecular epidemiological studies indicate that the proportion of $C$. parvum infections in humans is much higher in rural than in urban areas (Learmonth et al., 2004). 


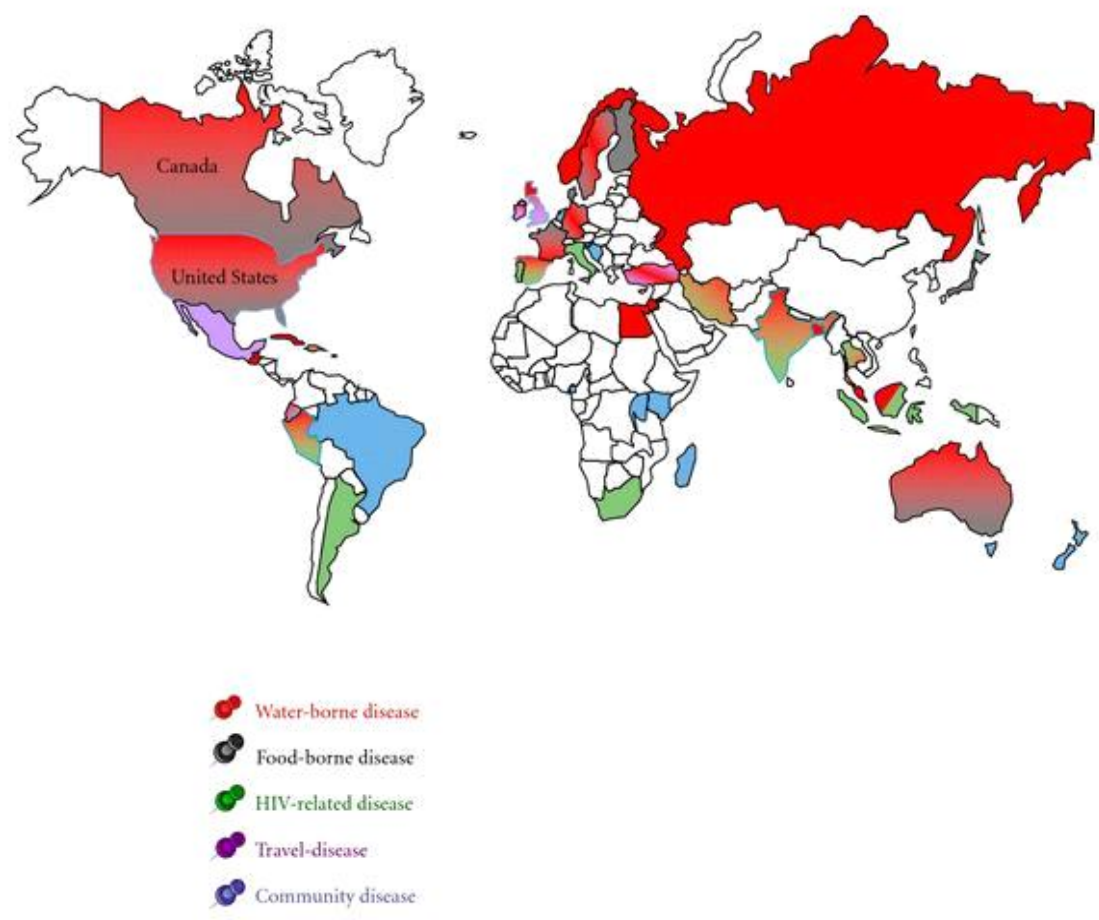

Source:Putignani,., and Menichella, . (2010)

Figure 2.Geography of worldwide occurrence of human cryptosporidiosis outbreaks and sporadic cases

\section{- Host Range}

In animals, it was found that different species of Cryptosporidium infect farm animal while fish, poultry, amphibians and reptiles are also susceptible (Thomson, 2016). Once Cryptosporidium was considered to cause opportunistic infection, but now, together with enterotoxic Escherichia coli (ETEC) and Rota- and Corona-viruses, it is an important component of the calf diarrhea complex (Gulliksen et al., 2009).Currently, 26 morphologically, biologically and molecular-biologically confirmed different Cryptosporidium species are listed (Fayer and Santin, 2009; Elwin et al., 2012; Lebbad et al., 2013; Adamu et al., 2014), having mammals (primates, bovidae, equidae, carnivora, hares, rabbits, tapiridae and rhinocerotidae), amphibians, reptiles and birds as hosts. Major species found in mammals are: C. andersoni, C. bovis, C. canis, C. fayeri, C. felis, C. hominis, $C$. macropodum, $C$. muris, $C$. parvum, $C$. ryanae, $C$. suis and $C$. wrairi. The three originally from birds isolated species are $C$. baileyi, $C$. galli and $C$. meleagridis, whereas $C$. serpentis, and $C$. varanii originate from reptiles and $C$. fragile from amphibians (Fayer, 2008).

\section{- Cattle}

There are four species of Cryptosporidium which are commonly found in cattle; C. parvum, C. bovis, $C$. ryanae and $C$. andersoni. There are some reports of other species also being found; $C$. hominis has been reported in a three day old calf and a six year old cow from Scotland (Smith et al., 2005), C. suis in a calf (Fayer et al., 2006) and C. felis in a cow (Bornay-Llinares et al., 199).

\section{- Sheep and goats}

Sheep and goats are predominantly infected with $C$. parvum, C. xiaoi, C. bovis and C. ubiquitum although rare occurrences of other species have been reported. Cryptosporidium hominis has been reported as the predominant species in sheep on the Scottish island of St Kilda (Connelly et al., 2013), in a sheep and a goat kid from a farm and petting zoo in the UK (Giles et al., 2009) and in a sheep in Australia (Ryan et al., 2005). Cryptosporidium scruforum and C. andersoni have been detected in sheep from flocks in Australia (Yang et al., 2014) and $C$. fayeri has been reported in a sheep (Ryan $e t$ al., 2005) again these occurrences of other species are rare.

\section{- Pigs}

The predominant species of Cryptosporidium detected in pigs are C. suis and C. scruforum; C. suis is prevalent in pigs worldwide but causes few clinical signs (Enemark et al., 2003). Cryptosporidium 
scruforum is a fairly new species, only described in 2013 (Kvac et al., 2013), again, this species does not seem to cause any clinical disease in pigs yet is prevalent in adult pigs worldwide. It does not appear infective to pigs under eight weeks of age (Kvac et al., 2014).

\section{- Poultry}

Three species of Cryptosporidium are currently known to infect birds; C. meleagridis, C. baileyi and C. galli. Avian cryptosporidiosis was first described in 1929 but was not formally recognised until 1955 when C. meleagridis was reported in turkeys (Sarah, 2016). C. meleagridis is found in the small and large intestine and bursa of infected birds. Cryptosporidium meleagridis has been reported in many different species of birds and also in humans (Silverlas et al., 2012; Ng-Hublin et al., 2013; Wang et al., 2014). The second species of Cryptosporidium to be reported in birds was C. baileyi in chickens in 1986 (Current et al., 1986), this species is more commonly associated with respiratory cryptosporidiosis in broiler chickens and is the most common species of avian Cryptosporidium. Also described from chickens is $C$. galli which was discovered in 1999 but was redescribed in 2003 (Ryan et al., 2003). Like C. meleagridis this species is also found in the small intestine, large intestine and in the epithelium of the proventriculus and is associated with clinical disease and mortality (Tumova $e t$ al., 2002). The three avian adapted species are morphologically different and can be distinguished by morphological difference in the size and shape of the oocysts (Sarah, 2016).

\section{- Fish}

In fish three species have been reported but it is possible that there are more which remain undiscovered as studies into the species of Cryptosporidium found in fish are scarce. The first species in fish to be described was $C$. molnari infecting the stomach of gilthead sea bream and European sea bass with few clinical signs (Alvarez-Pellitero and Sitja-Bobadilla, 2002). The other reported species of Cryptosporidium infecting fish is $C$. scophthalmi which is found in the intestinal epithelium of turbot (Thomson, 2016).

\section{- Amphibians and reptiles}

Four species of Cryptosporidium have been reported in amphibians and reptiles, C. fragile, C. varanii, $C$. serpentis and $C$. ducismarci. As its name suggests, $C$. fragile is the most delicate species of Cryptosporidium and was first described in the stomach of the black-spined toad (Jirku et al., 2008) and was named due to its fragile nature. Unlike other species of Cryptosporidium, C. fragile will crumple on contact with hypertonic solutions and disintegrate after just 4 weeks in water (Thomson, 2016). Cryptosporidium has been reported in many species of snakes and other reptiles, the first to be identified was $C$. serpentis which is a gastric species and was found in four snake species in 1977 (Brownstein et al., 1977).

\section{- Human}

In humans there are two species which are routinely diagnosed in clinical cases of cryptosporidiosis; these are the zoonotic species C. parvum and the human adapted species C. hominis (Morgan-Ryan et al., 2002). Cryptosporidiosis is highly dependent on the immune status of the host and thus, immunocompromised individuals can develop a chronic and life-threatening diarrheal disease while immunocompetent individuals most commonly develop acute self-limiting gastroenteritis. Due to their immature immune status, children are highly susceptible for infections with Cryptosporidium and routinely get infected by oral uptake of even low infective doses of the parasite's oocysts. It was estimated that 1 to $10 \%$ of the populations in developing countries were infected with Cryptosporidium, wherein 1-to-9-year-old children and toddlers were the most affected groups (Chen et al., 2003). Moreover, the intestinal malabsorption caused by cryptosporidiosis in developing countries further affects particularly malnourished children (Desai et al., 2012).

A true host specificity of the species in most cases, however, does not exist and after C. baileyi, $C$. canis, C. felis, C. meleagridis, C. bovis, C.suis, C. andersoni and C. muris also were detected in cases of human cryptosporidiosis, these species, further to $C$. parvum, also have to be considered potentially zoonotic (Helmy et al., 2013). The zoonotic potential of these species has to be judged as lower, although not in immunosuppressed persons (Lendner et al., 2011).

. Cryptosporidium parvum (C. parvum) infects a number of mammalian hosts whereas $C$. hominis infects only humans (Leav et al., 2003). Despite their identical morphology, the two species can be 
distinguished by molecular methods. Some studies have also shown a lot of heterogeneity among the genotype 1 (C. hominis) isolates. The heterogeneity is seen at the Cpgp40/15 (also known as gp60/45/15) locus which encodes for surface glycoproteins present during the invasive stages of the parasite (Strong et al., 2000).

Table 1.Species of cryptosporidium with their characteristics

\begin{tabular}{|c|c|c|c|c|c|}
\hline $\begin{array}{l}\text { Cryptosporidium } \\
\text { species }\end{array}$ & $\begin{array}{l}\text { Mean oocyst } \\
\text { dimensions } \\
(\mu \mathrm{m}) \mathrm{a}\end{array}$ & Major host(s) & $\begin{array}{l}\text { Usual site of } \\
\text { infection }\end{array}$ & \multicolumn{2}{|c|}{$\begin{array}{l}\text { Infections reported in } \\
\text { humans }\end{array}$} \\
\hline C. andersoni & $7.4 \times 5.5$ & Cattle & Stomach & \multicolumn{2}{|c|}{ Yes, but only rarely } \\
\hline C. baileyi & $6.2 \times 4.6$ & Poultry & $\begin{array}{l}\text { Upper respiratory } \\
\text { tract, }\end{array}$ & \multicolumn{2}{|l|}{ No } \\
\hline $\begin{array}{l}\text { C. bovis } \\
\text { (previously bovine } \\
\text { B genotype) }\end{array}$ & $4.9 \times 4.6$ & Cattle & Small intestine & \multicolumn{2}{|c|}{ Yes, but only rarely } \\
\hline $\begin{array}{l}\text { C. canis } \\
\text { (previously dog } \\
\text { genotype) }\end{array}$ & $5.0 \times 4.7$ & Dog & Small intestine & \multicolumn{2}{|l|}{ Yes, occasionally } \\
\hline $\begin{array}{l}\text { C. cichlidis } \\
\text { (previously } \\
\text { piscine genotype } 1 \\
\text { or C. molnari-like) }\end{array}$ & $4.6 \times 4.4$ & Tilapia & Stomach & \multicolumn{2}{|l|}{ No } \\
\hline $\begin{array}{l}\text { C. } \text { cuniculus } \\
\text { (previously rabbit } \\
\text { genotype) }\end{array}$ & $5.6 \times 5.4$ & Rabbit, humans & Small intestine & \multicolumn{2}{|c|}{$\begin{array}{l}\text { Yes, occasionally. One } \\
\text { waterborne outbreak }\end{array}$} \\
\hline C. ducismarci & & Tortoises & Intestine & \\
\hline C. erinacei & $4.9 \times 4.4$ & Hedgehog & Small intestine & \multicolumn{2}{|c|}{ Yes, but only rarely } \\
\hline $\begin{array}{l}\text { C. fayeri } \\
\text { (previously } \\
\text { marsupial } \\
\text { genotype I) }\end{array}$ & $4.9 \times 4.3$ & Marsupials & Intestine & \multicolumn{2}{|c|}{ Yes, but only rarely } \\
\hline C.felis & $4.6 \times 4.0$ & Cat & Small intestine & \multicolumn{2}{|l|}{ Yes, occasionally } \\
\hline C. fragile & $6.2 \times 5.5$ & $\begin{array}{l}\text { Black spined } \\
\text { toad }\end{array}$ & Stomach & \multicolumn{2}{|l|}{ No } \\
\hline C. galli & $8.3 \times 6.3$ & Chicken & Proventriculus & \multirow{2}{*}{\multicolumn{2}{|c|}{$\begin{array}{l}\text { No } \\
\text { Yes, commonly. Outbreaks } \\
\text { are reported }\end{array}$}} \\
\hline $\begin{array}{l}\text { C. hominis } \\
\text { (previously } \\
\text { referred to as C. } \\
\text { parvum human } \\
\text { genotype, } \\
\text { genotype } 1 \text {, and } \\
\text { genotype } \mathrm{H} \text { ) }\end{array}$ & $4.9 \times 5.2$ & Humans & Small intestine & & \\
\hline C. huwi & $4.6 \times 4.4$ & Guppy & Stomach & No & \\
\hline $\begin{array}{l}\text { C. macropodum } \\
\text { (previously } \\
\text { marsupial } \\
\text { genotype II) }\end{array}$ & $5.4 \times 4.9$ & $\begin{array}{l}\text { Eastern grey } \\
\text { kangaroo }\end{array}$ & Intestine & No & \\
\hline C. meleagridis & $5.2 \times 4.6$ & Birds, mammals & Intestine & $\begin{array}{l}\text { Yes, frequency } \\
\text { depends on } \\
\text { setting. One } \\
\text { farm-related and } \\
\text { one school- } \\
\text { related outbreak }\end{array}$ & \\
\hline C. molnari & $4.7 \times 4.5$ & Sea bream & Intestine & No & \\
\hline C. muris & $7.0 \times 5.0$ & Rodents & Stomach & $\begin{array}{l}\text { Yes, but only } \\
\text { rarely }\end{array}$ & \\
\hline $\begin{array}{l}\text { C. parvum (also } \\
\text { sometimes } \\
\text { previously called } \\
\text { bovine genotype, } \\
\text { genotype II, and }\end{array}$ & $5.0 \times 4.5$ & $\begin{array}{l}\text { Humans, pre- } \\
\text { weaned } \\
\text { mammalian } \\
\text { livestock }\end{array}$ & Small intestine & $\begin{array}{l}\text { Yes, commonly } \\
\text { and outbreaks } \\
\text { are reported } \\
\text { frequently }\end{array}$ & \\
\hline
\end{tabular}




\begin{tabular}{|c|c|c|c|c|}
\hline genotype B) & & & & \\
\hline C. proliferans & $7.7 \times 5.3$ & Rodents & Stomach & No \\
\hline $\begin{array}{l}\text { C. ryanae } \\
\text { (previously deer- } \\
\text { like genotype) }\end{array}$ & $3.7 \times 3.2$ & Cattle & Small intestine & No \\
\hline $\begin{array}{l}\text { C. } \\
\text { reichenbachklinkei } \\
\text { (previously } \\
\text { piscine genotype } \\
\text { 2) }\end{array}$ & $3.4 \times 3.4$ & Gourami & Stomach & No \\
\hline $\begin{array}{l}\text { C. scrofarum } \\
\text { (previously pig } \\
\text { genotype II) }\end{array}$ & $5.2 \times 4.8$ & Pig & Small intestine & $\begin{array}{l}\text { Yes, but only } \\
\text { rarely }\end{array}$ \\
\hline C. rubeyi & $4.7 \times 4.3$ & $\begin{array}{l}\text { Ground } \\
\text { squirrels }\end{array}$ & & No \\
\hline C. serpentis & $6.2 \times 5.3$ & Reptiles & Stomach & No \\
\hline $\begin{array}{l}\text { C. suis (previously } \\
\text { pig genotype I) }\end{array}$ & $4.6 \times 4.2$ & Pig & Small intestine & $\begin{array}{l}\text { Yes, but only } \\
\text { rarely }\end{array}$ \\
\hline $\begin{array}{l}\text { C. tyzzeri } \\
\text { (previously mouse } \\
\text { genotype I) }\end{array}$ & $4.6 \times 4.2$ & Mice & Small intestine & $\begin{array}{l}\text { Yes, but only } \\
\text { rarely }\end{array}$ \\
\hline $\begin{array}{l}\text { C. ubiquitum } \\
\text { (previously } \\
\text { cervine genotype) }\end{array}$ & $5.0 \times 4.7$ & $\begin{array}{l}\text { Various } \\
\text { mammals }\end{array}$ & Small intestine & $\begin{array}{l}\text { Yes, } \\
\text { occasionally }\end{array}$ \\
\hline C. viatorum & $5.4 \times 4.7$ & Humans & & $\begin{array}{l}\text { Yes, } \\
\text { occasionally }\end{array}$ \\
\hline $\begin{array}{l}\text { C. varanii (syn. C. } \\
\text { saurophilum) }\end{array}$ & $4.8 \times 4.7$ & Reptiles & Intestine & No \\
\hline C. wrairi & $5.4 \times 4.6$ & Guinea pig & Small intestine & No \\
\hline $\begin{array}{l}\text { C. xiaoi } \\
\text { (previously C. } \\
\text { bovis-like } \\
\text { genotype or C. } \\
\text { bovis from sheep } \\
\text { or C. agni) }\end{array}$ & $3.9 \times 3.4$ & Sheep, goat & & No \\
\hline
\end{tabular}

Source: Yosra (2014)

\section{- Transmission and Source of Cryptosporidium}

Cryptosporidium oocysts are transmitted between hosts via the fecal-oral route, either directly from contact with faeces of infected animals or indirectly through environmental contamination or from ingestion of contaminated food or water. Transmission is by the faecal-oral route and may involve a vehicle such as contaminated food or drinking water. Calves usually become infected by the oral uptake of oocysts from the environment. Possible major sources of infection, next to infected and shedding neighbor animals, are contaminated stables, faeces and dirty teats and udders of suckling cows (Yosra, 2014).

Cryptosporidium parvum is highly infectious for young livestock and humans; older livestock can remain infected and excrete oocysts that can be transmitted to other susceptible hosts. Oocysts can survive for long periods ( $>6$ months) in cool, moist environments, and on fomites such as farm gates, buildings and utensils. Oocysts can be transmitted following direct contact with faeces from an infected individual, or contact with contaminated fomites, or by ingestion of contaminated food or water. Transmission of $C$. hominis is considered to be anthroponotic (Flores and Okhuysen, 2009; Borad and Ward 2010; Yang et al., 2010). Impact of water livestock on transmission is waterborne contamination is a growing concern causing widespread disease outbreaks. Factors that have contributed to the emergence of cryptosporidiosis in animals include increased environmental contamination and trends in livestock production (Borad and Ward, 2010).

In humans the zoonotic nature of infection, along with increased numbers of at-risk population have contributed to the rate intensification of the disease (Mosier and Oberst, 2000). There are some reports of veterinary students, typically from urban areas, becoming infected with $C$. parvum when they start 
working with farm livestock (usually calves) during their studies (Preiser et al., 2003; Gait et al., 2008) as well as outbreaks amongst members of the public associated with petting zoos or farm visits (Gormley et al., 2011). Cryptosporidium can be transmitted from animals to humans through direct contact. This has occurred with veterinary workers (Preiser, 2003) and other people exposed to animals (Stantic- Pavlinic, 2003), particularly farm workers (Mahdi and Ali, 2002), and in animal nursery fair (Ashbolt, 2003). Retrospective analysis of samples collected at the time of the outbreak has infected hosts can shed huge numbers of oocysts per day, which are immediately infective to other susceptible hosts meaning that infection can pass very quickly between animals kept in close contact to one another (Nydam et al., 2001; Zambriski et al., 2013).

\section{- Risk Factors}

The factors that make animals susceptible to infection and that predispose infected animals to develop clinical disease are not well understood. Disease in agricultural animals associated with infection with Cryptosporidium is associated with infection with $C$. parvum and there is little evidence that infection with $C$. andersoni is associated with disease. Commonly, other enteric infections are present where there is disease attributed to Cryptosporidium. The site of infection with C.parvum is on the enterocyte where it results in cell damage, loss of brush border enzymes and a reduction of villous surface area (Radostits et al., 2006).

\section{- Age}

There is a significant association between age and risk of infection with Cryptosporidium. Cryptosporidiosis due to $C$. parvum is predominantly a problem of neonate animals with maximum rate of excretion of oocysts between the age of 4 and 21 days. According to Huetink et al. (2001); Xiao et al. (2004) and Nguyen et al. (2007), age appeared to be an important factor that influences the occurrence of the Cryptosporidium. The calves under 3 months are at higher risk of infection compared to the older ones. The higher prevalence in this age group can be attributed to the fact that these age groups are highly susceptible to the disease because of the immature immune system of the animal at this age (Regassa, A., 2009). Kvac et al., (2006) explained that the animal is becoming resistant with age due to the immune development through time.

Although exceptions occur, older animals generally develop poor infections, even when unexposed previously to this parasite (Xiao et al., 2004) age-related resistance, unrelated to prior exposure, has been observed in lambs but not calves (Radostits et al., 2006). The common occurrence of cryptosporidiosis in young animals reflects their susceptibility to infection with a low number of oocysts and common exposure to oocysts (Fayer, R. and L. Xiao, 2008).

\section{- Pathogen risk factors}

Oocysts are resistant to most disinfectants and can reportedly remain viable for about 18 months in a cool, damp or wet environment, can survive for several months in soil and slurry, but are susceptible to desiccation and temperatures above $60^{\circ} \mathrm{c}$. The infectivity of the oocysts can be destroyed by ammonia, formalin, freeze-drying and exposure to temperatures below $\mathrm{O}^{\circ} \mathrm{C}\left(32^{\circ} \mathrm{F}\right)$ and above $65^{\circ} \mathrm{C}$ $\left(149^{\circ} \mathrm{F}\right)$. Ammonium hydroxide, hydrogen peroxide, chlorine dioxide, $10 \%$ formol saline and $5 \%$ ammonia are effective in destroying the infectivity of the oocysts. The infectivity of oocysts in calf feces is reduced after 1-4 days of drying (Radostits et al., 2006).

\section{- Concurrent infections}

Concurrent infections with other enteropathogens, especially rotavirus and coronavirus, are common and epidemiological investigsation suggest that diarrhea is more severe with mixed infections. Mixed infections are most common, but cryptosporidia infection can be significant in its own right. Immunologically compromised animals are more susceptible to clinical disease than immunocompetent animals, but the relationship between disease and failure of passive transfer of colostral immunoglobulins is not clear. The disease can be reproduced in both colostrum-deprived and colostrum fed calves and, in the field, clinical disease can occur in calves and foals with adequate passive transfer of colostral immunoglobulins. However, the shedding of the organism has been observed to be higher in calves with low absorptive efficiency of $\mathrm{IgG}$ from colostrum and low serum IgG concentrations (Radostits et al., 2006).

\section{- Immune Status}

Undeveloped immune systems are The usually seen in young livestock and human infants Weakened immune systems may be seen in animals suffering from other diseases, elderly humans and 
malnourished persons; individual's receiving chemotherapy or corticosteroid therapy and HIV positive individuals(Suleiman and Xiao, 2001). These individuals experiences increased mortality, decreased weight gain or weight loss and generally poorer performance overall when compared to healthy animals. Additionally, infected animals represent a potentially large source of oocysts that can contaminate water and foods used for human consumption. A single infected calf can excrete up to 10 billion oocysts during a 2 weeks infection (Douglus, 1999).

\section{- Morbidity and Mortality}

Cryptosporidium is the cause of diarrhea in man and one of the more common opportunistic pathogen affecting human patient with AIDS. High morbidity which results in production losses and death of live animals from its high mortality specially, in calves and immunocompromissed individuals are significant problems to farm owners (Thomson, 2014). Morbidity and Mortality in North America, approximately $2 \%$ of the population is infected and $80 \%$ has been exposed at some time. Worldwide; the prevalence is 1 to $4.5 \%$ in developed countries and 3 to $20 \%$ in developing countries. In healthy people the infection is usually self-limiting and resolves after 2 to 4 days; however, episodes of diarrhea lasting 1 to 4 weeks have been seen at some day care centers. Cryptosporidiosis infections may develop in immunosuppressed individuals, particularly AIDS patients; these infections may be debilitating and contribute to death. Estimated infection rates in AIDS patients range from 3 to $20 \%$ in the United States and 50 to $60 \%$ in Africa and Haiti (CFSPH, 2005).

\section{- Pathogenesis}

Calves usually become infected with Cryptosporidium between the age of one to four weeks and the duration of disease is short; it lasts maximally up to two weeks (Fayer et al., 2000; Ralston et al., 2003). Calves begin shedding oocysts as early as in the age of two days. The peak shedding occurs with 14 days of age (Olson et al., 2004). The pathogenesis of Cryptosporidium induced diarrhea is believed to result from parasite invasion and epithelial destruction with the result of mild to moderate villus atrophy and microvillii shortening and destruction (deGraaf et al., 1999). This will lead to impaired nutrient absorption and transport. The main clinical manifestations of C. parvum in cattle are diarrhea, depression, anorexia and abdominal pain (Ralston et al., 2003; Fayer et al. 2000). In general clinical cryptosporidiosis is observed in calves of the age of 7-30 days. It lasts 4-14 days. The severity and duration are highly variable among calves (Olson et al., 2004). The diarrhea, which is pale yellow with mucus, can be mild to severe and can last up to two weeks resulting in lethargic, anorexic and dehydrated calves. In severe cases, calves die from dehydration and cardiovascular collapse. Other enteric viral, bacterial and parasitic pathogens such as Rotavirus, Escherichia coli and coccidia could also be observed in calves during the first four weeks of life. This exaggerates the severity of cryptosporidiosis (Joachim et al., 2003). Calves with severe cryptosporidiosis take four to six weeks to fully recover which causes an initial negative impact on the production (Ralston et al., 2003).

\section{- Clinical Signs}

There is no clinical findings characteristic of diarrhea due to infection with $C$. parvum in calves. In general, calves are usually 5-15 days old and have a mild to moderate diarrhea which persists for several days regardless of treatment. The age at onset is later, and the duration of diarrhea tends to be a few days longer, than the diarrheas associated with rotavirus, coronavirus, or enterotoxigenic Escherichia coli. The persistent diarrhea results in marked loss of body weight and emaciation in some cases. In most cases, the diarrhea is self-limiting after several days. Varying degrees of apathy, reduced feed intake and dehydration are present. Only rarely does severe dehydration, weakness and collapse occur, in contrast to other causes of acute diarrhea in neonatal calves drying (Radostits et al., 2006). The clinical symptoms of Cryptosporidium differ between non-immunocompromised and immunocompromised individuals. In non immunocompromised individuals, the disease is usually a self-limiting acute gastroenteritis, characterized by vomiting, weight loss, fever, watery diarrhoea, cramping, abdominal pains, flatulence, malaise and myalgia (Chin, 2000).

In animals, cryptosporidiosis is mainly observed in young calves and the severity of the disease depends on several factors such as host immunity, infective dose and current infection with other pathogens such as rotaviruses. Symptoms vary from asymptomatic to pasty or watery profuse diarrhea, dehydration and mortality. C. parvum, together with enterotoxic Escherichia coli and Rota- 
and Corona-viruses, is an essential component of the calf diarrhea complex (diarrhea within the first three weeks) and by this is one of the major causes of losses in calf rearing (Yosra, 2014).

The clinical picture of the neonatal diarrhea within a mono- or also mixed-infection with C. parvum is characterized by profuse, yellowish diarrhea and its consequences, like exsiccosis, metabolic acidosis and loss of electrolytes (Kaske et al.,2008). These become manifest in form of caved in bulbi, decreased skin turgor, coolish acra and general infirmity. Case fatality rates can be high in herds with cryptosporidiosis when the calf feeder withholds milk and feeds only electrolyte solutions during the episode of diarrhea. The persistent nature of the diarrhea leads to a marked energy deficit in these circumstances and the calves die of inanition at 3-4 weeks of life. This syndrome may be particularly common in the winter months where there is additional cold stress affecting energy requirements. Feed intake is reduced and, combined with the persistent diarrhea over several days, may cause emaciation. Recovery occurs between 6 and 10 days after the onset of diarrhea (Radostits et al., 2006).

\section{- Diagnosis}

Diagnosis of cryptosporidiosis is traditionally based on the detection of fecal oocysts. The oocysts can be detected in the feces by examination of fecal smears with certain stains, by fecal flotation, or by immunologically assisted methods. Current diagnostic techniques used in most clinical laboratories include the immunofluorescent assay visualization of fecal oocysts. It has been suggested that, if the diarrhea is associated with cryptosporidia, the feces should contain 105-107 oocysts per $\mathrm{mL}$ of feaces (Radostits et al., 2008).

\section{- Parasitological diagnosis}

Several methods exist to detect Cryptosporidium in fecal samples. Among them the most common method is microscopy for the detection of oocysts. Fecal samples can be examined directly on slides or after concentration either by flotation or sedimentation to remove fecal debris or to concentrate the number of oocysts; the detection of oocysts in animals with low numbers of oocysts is facilitated (Fayer and Xiao, 2007). Visualization of Cryptosporidium oocysts by microscopy most commonly done by direct smear and without any staining and by the modified Ziehl-Neelsen stain under light microscopy, whereby the oocysts stain purple with blue background. Immunofluorescence staining techniques using monoclonal antibodies against the oocyst wall antigen under epifluorescence microscopy are also useful. Immunofluorescent antibody-based (IFA) procedures have a high sensitivity, but still the easier and cheaper traditional staining methods such as the Ziehl-Neelsen stain are widely used, despite their lower sensitivity (Caccio and Widmer, 2014). Most parasitological detection methods for Cryptosporidium do not distinguish between viable and nonviable oocysts (Yosra, 2014).

\section{- Serological diagnosis}

Serological methods are particularly useful tools for screening of large numbers of samples, like in epidemiological surveys. Most serological tests used to identify exposure/infection are enzyme linked immunosorbent assays (ELISA) or enzyme-linked immunoelectrotransfer blots (EITB; Western blot) employing various aqueous extracts of $C$. parvum oocysts (Yosra, 2014). Enzyme immunoassay (EIA) methods are fast, inexpensive, easy to be performed, and show sensitivity comparable to that of the immunofluorescence methods (Fayer and Xiao, 2007). Rapid immunochromatographic (strip) tests can be also used. These tests rely on the detection of cell wall proteins of the oocysts using monoclonal antibodies (Papini and Cardini, 2006).

\section{- Molecular detection of Cryptosporidium}

Several nucleic acid detection techniques are described for the detection of Cryptosporidium, some of which may be able to distinguish viable from nonviable ocysts (Egyed et al., 2002). Species differentiation using molecular methods can be done in a few different ways; these begin with DNA extraction from oocysts and PCR amplification of the gene(s) of interest. DNA extracted from oocysts can be amplified using standard or nested PCR methods. This is useful if the sample only contains a small amount of DNA as it results in more DNA copies than standard PCR. Species can be differentiated using restriction enzymes to digest PCR products into fragments of different sizes (PCR Restriction Fragment Length Polymorphism (RFLP)) and these fragments can be visualised on the agarose gel, producing varying banding patterns depending on species (Sulaiman et al., 1999). 
Another PCR method which can be used to detect and speciate Cryptosporidium parasites is real-time PCR which is considered to be the "gold-standard" for Cryptosporidium detection as this method is the most sensitive and can detect as few as 2 oocysts per PCR (Hadfield et al., 2011). In real-time PCR the amplification of the DNA can be tracked in "real time" and the amount of DNA present can be quantified, this is an advantage over standard PCR which can only indicate the presence of parasite DNA but cannot quantify the amount (Chalmers et al., 2011).

\section{- Differential Diagnosis of Cryptosporidium}

The differential diagnosis for Cryptosporidium includes other entero-pathogens involved in diarrhoea. Multiple pathogens can be present including other parasites, rotavirus, coronavirus, pathogenic strains of E. coli and Salmonella spp. Cryptosporidiosis in livestock is confirmed by finding significant numbers of oocysts in diarrhoeic faeces in the absence of other pathogens, and although it has been widely speculated that co-infection may lead to more severe cryptosporidiosis (Lorenz et al., 2011) but experimental data to support this are lacking.

A differential diagnosis list for cryptosporidiosis includes Giardia, Isospora, microsporidia, Salmonella, rotavirus and other diarrheal diseases. Cryptosporidiosis can be diagnosed by finding $C$. parvum after a fecal flotation in either sucrose or zinc sulfate solutions. The mature oocysts are 4-5 $\mu \mathrm{m}$ in diameter and contain four thin, flat, motile sporozoites. Cryptosporidium parvum can also be detected through an acid-fast staining. Oocysts are not shed continuously and repeated sampling may be necessary. The oocysts appear red after the staining. Immunofluorescence can also be used to detect Cryptosporidium in feces. Finally, cryptosporidiosis can be detected by stained biopsy/necropsy specimens or fresh intestinal scrapings (CFSP H, 2011).

\section{- Therapeutics}

At present there are very few products licensed in the treatment or prevention of cryptosporidiosis in livestock or humans, the few products which are available are not very effective and in most cases will only reduce the duration of shedding and have little or no effect on immunocompromised patients. The only licensed treatment for cryptosporidiosis in calves is halofuginone lactate which affects invading parasite stages of Cryptosporidium (Jarvie et al., 2005). This drug is approved for use in both prevention and treatment of cryptosporidiosis in calves at a dose of $0.10 \mathrm{mg} / \mathrm{kg}$ of body weight per day for seven consecutive days. As a preventative measure the drug should be given within 48 hours of birth and as a therapeutic, within 24 hours of the onset of symptoms. Treatment with halofuginone lactate does not completely prevent or cure disease but it does reduce oocyst shedding and duration of diarrhoea (Jarvie et al., 2005; Trotz-Williams et al., 2011). But there is no licensed treatment for cryptosporidiosis in sheep, goats or pigs (Viu et al., 2000). However, a few coccidiostats, such as decoquinate have been tested against Cryptosporidium with limited or no reduction in oocyst shedding (Moore et al., 2003).

In human, Nitazoxanide, a nitrothiazolylsalicylamide was approved for the treatment of cryptosporidiosis. The efficacy of Nitazoxanide without an efficient immune system (number of CD4 cells) seems to be limited; several authors therefore only at test a partial efficiency (Cabada and White, 2010).

\section{- Supportive therapy}

Affected calves should be supported with fluids and electrolytes, both orally and parenterally as necessary until spontaneous recovery occurs. Cows' whole milk should be given in small quantities several times daily to optimize digestion and to minimize loss of body weight. It is important to continue to feed mill to the full level of requirement despite the presence of diarrhea, as a reduction in intake may lead to death from inanition. Several days of intensive care and feeding may be required before recovery is apparent. Parenteral nutrition could be considered for valuable calves (Radostits $e t$ al., 2006).

\section{- Control and Prevention}

Cryptosporidium organisms are common in the environment and can be carried by animals without any symptoms. Keeping sick animals away from the healthy animals is a good way to limit exposure. Chlorine does not effectively kill the organism and it is resistant to many disinfectants. Clean and disinfectant (5\% ammonia solution can work) areas where sick animals have been or had diarrhea. 
Also, provide good nutrition to the animals and keep the animals healthy to minimize the risks (Radostits et al., 2008).

Cryptosporidiosis is a difficult disease to control, as the oocysts are very environmentally stable and can survive for long periods of time in cool, moist conditions, infected animals shed huge numbers of infective oocysts (Fayer et al., 2010) and infection can pass through a group of susceptible hosts very quickly. The oocysts are also resistant to many disinfectants (Chalmers and Giles, 2010), there are no vaccines available to prevent the disease, and treatment options are limited and often rely on rehydration therapy. Good hygiene, such as preventing environmental contamination and proper disposal of contaminated material, are the most important ways to prevent infection (Radostits et al., 2008). Oocysts are resistant to most standard purification techniques, including filtration and chlorination. Reducing oocyst contamination of water sources are thought to offer the best protection from waterborne disease. Removal of the oocysts from drinking water by either boiling or by filtering the water through a filter with a pore size of $<1 \mu \mathrm{m}$ is also recommended for AIDS patients (Leav et al., 2003).

Many recommendations have been made for the prevention and control of infections in specific locations; such at hospitals, laboratories, day care centers, households, zoos and farms. These recommendations have basically involved managerial practices designed to minimize host contact with sources of infection and the use of different disinfection procedures to destroy infective oocysts (Haileeyesus, 2010). Diarrheic calves should always be isolated from healthy calves during the course of the diarrhea, and for several days after recovery. Sick calves are commonly treated by the same person who feeds the healthy calves and great care must be taken to avoid mechanical transmission of infection. Calf-rearing houses should be vacated and cleaned out on a regular basis; an all-in all-out management system, with thorough cleaning and several weeks of drying between batches of calves, should be used (Radostits et al., 2006).

Prevention and control of cryptosporidiosis require continued efforts to interrupt the transmission of Cryptosporidium through water, food, and contact with infected persons and animals. Hygiene measures at any setting are essential. Particularly, continuous improvement and monitoring of respective run-off water sources and none treated water. Veterinarians could play a role in implementing hygiene measures to be adopted and regulated in the farm animal environment, but access of animals to surface and canal water realistically cannot be restricted. Prevention and control programs will have to be multifaceted. Land-use regulations, economic incentives, and educational efforts towards behavioral change may be necessary for the implementation and the success of longterm strategies (Yosra, 2014).

Vaccination has been proposed as a method to control cryptosporidiosis in animal populations (Jenkins, 2001; Riggs, 2002). Immunodominant Cryptosporidium antigens have been identified from natural infections and subunit vaccines have been prepared for the use in calves (Jenkins, 2001). However, it became obvious that using active and passive immunization approaches can reduce clinical signs but in most cases it could not eliminate or reduce the oocyst shedding. Nonspecific agents in milk, such as the epidermal growth factor have been shown to protect enterocytes from parasite-induced patho-physiological alterations (Buret et al., 2003). Immunoprophylaxis; Hyperimmune bovine colostrum can reduce the severity of diarrhea and the period of oocyst excretion in experimentally infected calves and lambs. Protection is not related to circulating levels of specific antibody but requires a high titer of $C$. parvum antibody in the gut lumen for prolonged periods (Radostits et al., 2006).

\section{Public Health importance of Cryptosporidium}

Waterborne contamination is a growing concern causing widespread disease outbreaks. Cryptosporidium now additionally is considered an important food-borne pathogen causing a disease of socioeconomic significance worldwide (Putignani and Menichella, 2010). Factors that have contributed to the emergence of cryptosporidiosis in animals include increased environmental contamination and trends in livestock production. In developing countries the impact of protozoan pathogens represents a major cause of gastrointestinal illness and is becoming of growing impact. Cryptosporidium accounts for up to $20 \%$ of all cases of childhood diarrhea in developing countries and is a potentially fatal complication of AIDS (Mosier and Oberst, 2000). 
Current evidence indicates that the main reservoirs of zoonotic Cryptosporidium remain livestock, with the potential transmission of $C$. parvum although other species, and genotypes, have been reported in humans but only occasionally (Slapeta, 2013). Susceptibility to infection with other host adapted species and genotypes are largely governed by the immune status of the host (Slapeta, 2013).

Interestingly, although cattle have been repeatedly implicated as sources of water-borne outbreaks, the application of genotyping procedures to the contaminating isolate(s) has often incriminated human effluent as the source (Hunter and Thompson, 2005). The risk of infection appears greater within rural environments than within urban areas; presumably because of the increased opportunity for both direct and indirect transmission to occur in areas with poor sanitation and higher contact rates with domestic animal reservoirs of infection (Thompson and Smith, 2011).

The infection, however, is affected by the type of infecting isolates and the immune status of the host (Teunis et al., 2002). The incubation period ranges from 3-22 days with an average of one week (Checkley et al., 1998). Cryptosporidiosis more often affects children who are less than 3 years of age. In the developing countries it is a cause of death in immunocompetent infants who are less than 2 years of age (Xiao et al., 2001). The main clinical symptoms are a self limiting gastrointestinal illness, abdominal cramps and nausea, fever, vomiting, headache and growth retardation as well as other asymptomatic infections (Checkley et al., 1998). An infected patient can excrete more than 10 oocysts/g of faeces (McLauchlin et al., 1999). In immunocompressed patients cryptosporidiosis causes chronic, fulminant, transient or relapsing diarrhea which has even been associated with mortality (Manabe et al., 1998). The infection may spread throughout the alimentary canals and other mucosal surfaces, including the stomach and the biliary, the urinary or the respiratory tracts (Clemente et al., 2000; Megremis et al., 2004).

The economic impact of cryptosporidiosis, stemming from lost productivity, is enormous. Cryptosporidium infection in livestock may cause important economic impact to farmers because of its high morbidity and sometimes mortality rates among farm animals. Cryptosporidiosis, especially in young animals, can cause severe illness or death, resulting in decreased performance and production loss and results in financial loss to the producers from both extra care and supportive therapy needed and the death of production animals (Xiao et al., 2004). It also economic losses are short-term due to treatment costs of the diarrhea and longer term due to significant morbidity, impairment of growth, reduced weight gain and increased mortality in diseased animals (McDonald, 2000).

\section{CRYPTOSPORIDIUM INFECTION IN ETHIOPIA}

The prevalence of cryptosporidiosis in Ethiopia is variable in different geographic regions, for example, there is higher prevalence of infection in the Afar region due to the low per capital coverage of clean potable drinking water supply and the intense association of the pastoralist population with domestic animals in comparison with Bishoftu, which is a modern urban center with potable water and limited contact with domestic animals. Other investigators have also reported that the prevalence of cryptosporidium species varies in different regions of the world and that species variability could occur in different geographic regions within a country (McLauchn et al., 2000).

Cryptosporidium is now becoming a common opportunistic intestinal parasite in Ethiopia even though it is not diagnosed routinely. Reports from different parts of the country showed different prevalence rates of cryptosporidiosis. Recently a study conducted in Lege Dini, rural area in

Dire-Dawa, showed the prevalence of cryptosporidiosis to be $12.2 \%$ (Ayalew et al., 2008).

However, some of the diagnostic methods for specific intestinal parasites, especially for the newly emerging opportunistic intestinal parasites, were not available to most of Ethiopian health institutions (Hileeyesus, 2010).

The prevalence of many intestinal protozoa parasites has been reported to be associated with the amount of rain fall (Enriquez et al., 1997). Studies in Central America, South Africa, Kuwait and India have also revealed a high peak incidence of Cryptosporidiosis in the rainy seasons (Iqbal et al., 2001). The same report was observed in eastern Ethiopia. With regard to this condition, the two water sources, Ali-spring and Diga dam, are highly exposed to runoff in the rainy season. Diga dam, 
especially, is totally changed into runoff water as a result of which the district water Resource Office is forced to close the dam and stops providing service to community during the rainy season. This shows that contamination of drinking water sources by runoff containing feaces of infected humans and animals is an inevitable phenomenon (Ayalew, 2006).

Molecular epidemiological studies have indicated the proportion of C.parvum infections in humans is much higher in rural than in urban areas (Learmonth et al., 2004). This could be due to zoonotic transmission of C.parvum from animals which are more prevalent in rural areas than urban. However, since the majority of study participants with Cryptosporidiosis in different studies were live in urban area and had limited contact with domestic animals, drinking water which usually is drawn from rural sources have been contaminated with cattle feaces could serve as the source of infection to urban peoples (Fikrie et al., 2008). It's also reported that large herds may have a heavier pathogen load because of increased density of animals that favors infection of great number of calves, which in turn, contaminate their surrounding environment (Radostits et al., 2008).

\section{CONClusion AND RECOMMENDATION}

Cryptosporidiosis is a worldwide zoonotic parasitic disease that infects wide variety of animals and humans while infected animals and humans shed a very high number of oocysts. Its transmission occurs through direct or indirect contact with feces of these shedders. Outbreaks illustrate the personto-person spread in institutions; animal contact during farm visits and contact with recreational waters, swimming pool visits, municipal drinking water and food are also different routes of transmission. Fatal diarrhea with malabsorption and dehydration occurs in young and immune compromised hosts. It has been reported that Cryptosporidiosis is highly prevalent in Ethiopia while documents on epidemiology and public health importance of it are scarce. Cryptosporidium are very resistant to adverse environmental factors and can survive for several months without losing its infectivity. To date, there is no effective therapeutic agent for Cryptosporidium infection but following adequate management and hygienic practices are paramount importance in the control and prevention of the disease. Based on the above conclusion the following recommendations are forwarded:

- Better management practices like stream-bank fencing, use all-in, all-out management system, isolate infected animals, cleaning and disinfection activities to limit environmental contamination with fecal matter and use protective materials when handling animals should be implemented.

- Awareness creation and extension service should be provided including healthy education to the farmers and other attendants.

- Swimming and direct drinking from lakes, streams and rivers should be avoided.

- Water should be pasteurized or boiled before consumption.

- Further studies are needed for effective treatment and implementation of sound prevention and control measures.

\section{REFERENCES}

Adamu, H., Petros, B., Zhang, G., Kassa, H., Amer, S., Ye, J., Feng, Y., and Xiao, L. (2014). Distribution and clinical manifestations of Cryptosporidium species and subtypes in HIV/AIDS patients in Ethiopia. PLoS Negl Trop Dis 8, e2831.

Alvarez-Pellitero, P., and Sitja-Bobadilla, A. (2002). Cryptosporidium molnari n. sp. (Apicomplexa: Cryptosporidiidae) infecting two marine fish species, Sparus aurata L.and Dicentrarchus labrax L. Int J Parasitol,32: 1007- 1021.

Ashbolt, R.H., Coleman, D.J., Misrachi, A., Conti, J.M., and Kirk, M.D. (2003). An outbreak of cryptosporidiosis associated with an animal nursery at a regional fair. Commun. Dis.Intell, 27:244-249.

Ayalew, D., Eleni,B., Endeshaw, T., and Beyene,P. (2008). Cryptosporidium and Giardia infection and drinking water sources among children in Lege Dini, Ethiopia. Trop.Med.Intern. Heal, 13: 472-475.

Ayalew,D. (2006). Assessment of the association of Cryptosporidium parvum Giardia Lamblia and Entamoeba histolytica/dispar infection prevalence with drinking water source among children in Lege Dini,adada, Legf bira Dire dawa,Easter Ethiopia. Master thesis Department of biology, AAU. Pp.68.

Barta, J. R. and R. C. Thompson. (2006). What is Cryptosporidium? Reappraising its biology and phylogenetic affinities. Trends Parasitol, 22: pp. 463-468. 
Borad, A. and Ward, H. (2010). Human immune responses in cryptosporidiosis. Future Microbiol., 5: 507-519.

Bornay-Llinares, F.J., da Silva, A.J., Moura, I.N., Myjak, P., Pietkiewicz, H., Kruminis-Lozowska, W., Graczyk, T.K., and Pieniazek, N.J. (1999).Identification of Cryptosporidium felis in a cow by morphologic and molecular methods. Appl. Environ. Microbiol, 65: 1455-1458.

Brownstein, D.G., Strandberg, J.D., Montali, R.J., Bush, M., and Fortner, J. (1977). Cryptosporidium in snakes with hypertrophic gastritis. Vet Pathol, 14: 606- 617.

Buret, A.G., Chin, A.C., and Scott, K.G.E. (2003). Infection of human and bovine epithelial cells with Cryptosporidium andersoni induces apoptosis and disrupts tight junctional ZO-1:effects of epidermal growth factor. Int. J. Parasitol, 33: 1363-1371.

Cabada, M.M., and White, A.C. (2010). Treatment of cryptosporidiosis: do we know what we think we know? Curr Opin Infect Dis, 23: 494-499.

Caccio, S.M. (2005). Molecular epidemiology of human cryptosporidiosis. Parassitologia, 47: 185-192.

Caccio, S.M., and Widmer, G. (2014). Cryptosporidium: Parasite and Disease. Springer,Wien, Heidelberg, New York, Dordrecht, London.

CFSPH (2005): Cryptosporidiosis - The Center for Food Security and Public Health, Lowa State university, http://www.cfsph.iastate.edu/Factsheets/pdfs/cryptosporidiosis.pdf, retrieved date, 16:4-2017.

Chalmers, R.M., and Giles, M. (2010). Zoonotic cryptosporidiosis in the UK -challenges for control. J Appl. Microbiol,109: 1487-1497.

Chalmers, R.M., Campbell, B.M., Crouch, N., Charlett, A., and Davies, A.P. (2011). Comparison of diagnostic sensitivity and specificity of seven Cryptosporidium assays used in the UK. J Med Microbiol, 60: 15981604.

Checkley, W., Epstein, L.D., Gilman, R.H., Black, R.E., Cabrera, L., and Sterling, C.R. (1998). Effects of Cryptosporidium parvum infection in Peruvian children: growth faltering and subsequent catch up growth. Am. J. Epidemiol, 148: 497-506.

Chen, W., Harp, J.A., and Harmsen, A.G. (2003). Cryptosporidium parvum infection in genetargeted B celldeficient mice. J Parasitol,89: 391-393.

Chen, X.M., Keithly, J.S., Paya, C.V., and LaRusso, N.F. (2002). Cryptosporidiosis. N Engl J Med,346:17231731.

Chin, J. (2000). Cryptosporidiosis. In: Chin, J.(ed) Control of Communicable Diseases manual, 17th edn. American Public Health Association, Washington, DC, pp. 134-137.

Clemente, C.M., Caramori, C.A., Padula, P., and Rodrigues, M.A. (2000). Gastric cryptosporidiosis as a clue for the diagnosis of the acquired immunodeficiency syndrome. Arq. Gastroenterol, 37: 180-182.

Connelly, L., Craig, B.H., Jones, B., and Alexander, C.L. (2013). Genetic diversity of Cryptosporidium spp. within a remote population of Soay Sheep on St. Kilda Islands, Scotland. Appl. Environ. Microbiol, 79: 2240-2246.

Current, W.L., and Garcia, L.S. (1991). Cryptosporidiosis. Clin Microbiol Rev, 4: 325-358.

Current, W.L., Upton, S.J., aand Haynes, T.B. (1986). The life cycle of Cryptosporidium baileyi n. sp. (Apicomplexa, Cryptosporidiidae) infecting chickens. J Protozool, 33: 289-296.

D. A. Mosier and R. D. Oberst, (2000). "Cryptosporidiosis: a global challenge," Annals of the New York Academy of Sciences, vol. 916: pp. 102-111.

Dawit, A. (2006). Association of cryptosporidium parvum, giardia lamblia and entamoeba Histolytica/dispar infection with drinking water sources among children in rural Part of dire- Dawa, Eastern Ethiopia, DVM, thesis, Addis Ababa University, pp: 3-9.

De Graaf, D.C., Vanopdenbosch, E., Ortega-Mora, L.M., Abbassi, H., and Peeters, J.E. (1999). A review of the importance of cryptosporidiosis in farm animals. Int J Parasitol,29: 1269-1287.

deGraaf, D.C. (1999). Speculation on whether a vaccine against cryptosporidiosis is a reality or fantasy. Int. J. Parasitol, 29: 1289-1306.

Desai, N.T., Sarkar, R., and Kang, G. (2012). Cryptosporidiosis: An under-recognized public health problem. Trop Parasitol, 2: 91-98.

Dillingham, R.A., Lima, A.A., and Guerrant, R.L. (2002). Cryptosporidiosis: epidemiology and impact. Microbes Infect, 4: 1059-1066.

Douglus, P. (1999). New insights into human cryptosporidiosis. Clinical Microbial Revenue., 12:554-563.

Egyed, Z., Sreter, T., Szell, Z., Beszteri, B., Dobos-Kovacs, M., Marialigeti, K., Cornelissen, A.W., and Varga, I. (2002). Polyphasic typing of Cryptosporidium baileyi: a suggested model for characterization of cryptosporidia. J Parasitol,88: 237-243. 
Elwin, K., Hadfield, S.J., Robinson, G., Crouch, N.D., and Chalmers, R.M. (2012). Cryptosporidium viatorum n. sp (Apicomplexa: Cryptosporidiidae) among travellers returning to Great Britain from the Indian subcontinent, 2007-2011. International Journal for Parasitology ,42: 675-682.

Endeshaw, T., Mohamod, H. and Tilahun,W. (2004). C. parvum and other intestinal parasites among diarrheal patients referred to EHNRI in Ethiopia. Ethiop.Med J,42:195-198.

Enemark, H.L., Ahrens, P., Bille-Hansen, V., Heegaard, P.M., Vigre, H.,Thamsborg, S.M., and Lind, P. (2003). Cryptosporidium parvum: infectivity and pathogenicity of the 'porcine' genotype. Parasitology, 126: 407416.

Enriquez, F.J., Avila, C.R., Santos, J.L.,Tanaka-kido, J., Vallejo, O. And Sterling, C.R. (1997).Cryptosporidium infections in Mexican children,clinical, nutritional, entropatogenic and diagnostic evaluations. Am.J.Trop.Med.Hyg.,56: 254-257.

Fayer, R. (2004). Cryptosporidium: A water-borne zoonotic parasite.Vet. Parasitol, 126: pp. 37-56.

Fayer, R. (2010). Taxonomy and species delimitation in Cryptosporidium. Exp. Parasitol., 124: 90-97.

Fayer, R., and Santin, M. (2009). Cryptosporidium xiaoi n. sp. (Apicomplexa: Cryptosporidiidae) insheep (Ovis aries). Vet Parasitol,164: 192-200.

Fayer, R., and Xiao L. (2008). Cryptosporidium andCryptosporidiosis. 2nd edition. Boca Raton, London, New York, CRC Press, pp: 1-450.

Fayer, R., and Xiao, L. (2007). Cryptosporidium and cryptosporidiosis, 2nd edition. CRC PressTaylor \& Francis Group, Boca Raton, London, New York, pp. 580.

Fayer, R., Santin, M., Trout, J.M., and Greiner, E. (2006). Prevalence of species and genotypes of Cryptosporidium found in 1-2-year-old dairy cattle in the eastern United States. Vet. Parasitol, 135: 105112.

Fayer, R., Trout, J. M., Lewis, E.J., Santin, M., Zhou, L., Lal, A.A., and Xiao, L. (2003). Contamination of Atlantic coast commercial shellfish with Cryptosporidium. Parasitol Res, 89: 141-145.

Fayer, R., Trout, J.M., and Jenkins, M.C. (1998). Infectivity of Cryptosporidium parvum oocysts stored in water at environmental temperatures. J Parasitol, 84: 1165-1169.

Fayer, R., U.M. Morgan, and S.J. Upton, (2000). Cryptosporidium as a Parasitic Zoonotic. International Journal of Parasitology, 30: pp. 1305-1321.

Fayer,R., (2008). General Biology. In: Fayer, R. \& Xiao, L. (Eds.) Cryptosporidium and cryptosporidiosis, 2nd ed. Boca Raton: CRC press, pp. 1-42.

Fayer. R., and Xiao, L. (2007). Cryptosporidium and cryptosporidiosis, 2nd edition. CRC Press Taylor and Francis Group, Boca Raton, London, New York, pp. 580.

Fikrie, N., Hailu, A. and Belete, H. (2008). Determination and enumeration of Cryptosporidium oocysts and Giardia cysts in Legedadi (Addis Ababa) municipal drinking water system. Ethiop. J. Health Dev, 22: 6870.

Flores, J. and Okhuysen, P.C. (2009). Host factors - genetics of susceptibility to infection with enteric pathogens. Curr. Opin. Infect. Dis., 22: 471-476.

Fujino, T., Matsui, T., Kobayashi, F., Haruki, K., Yoshino, Y., Kajima, J., and Tsuji, M. (2002).The effect of heating against Cryptosporidium oocysts. J Vet Med Sci,64: 199-200.

Gait, R., Soutar, R.H., Hanson, M., Fraser, C., and Chalmers, R. (2008). Outbreak of cryptosporidiosis among veterinary students. Vet Rec., 162: 843-845.

Gebru, K., \& Girma, M. (2000). Prevalence of Cryptosporidium infection in children at the pediatrics clinic of Jimma Hospital, Southwest Ethiopia. Ethiopian Journal of Health Science, 10: 123-127.

Gerasimos, J., and Zaharato,S. (2009). Cryptosporidiosis,Medical parasitology. Landes Bioscience USA, pp. 214-221.

Giles, M., Chalmers, R., Pritchard, G., Elwin, K., Mueller-Doblies, D., Clifton-Hadley, F. (2009). Cryptosporidium hominis in a goat and a sheep in the UK. Vet Rec., 164: 24-25.

Gormley, F.J., Little, C.L., Chalmers, R.M., Rawal, N., and Adak, G.K. (2011). Zoonotic cryptosporidiosis from petting farms, England and Wales, 1992- 2009. Emerg. Infect. Dis, 17: 151-152.

Gulliksen, S.M., Jor, E.,Lie, K.I., Hamnes, I.S., Loken, T., Akerstedt, J., and Osteras, O. (2009). Enteropathogens and risk factors for diarrhea in Norwegian dairy calves. J Dairy Sci, 92: 5057 -5066.

Hadfield, S.J., Robinson, G., Elwin, K., and Chalmers, R.M. (2011). Detection and differentiation of Cryptosporidium spp. in human clinical samples by use of real time PCR. J Clin. Microbiol,49: 918-924.

Haileeyesus, A. (2010). The prevalence of intestinal parasitesand molecular characterization of Cryptosporidium species in Ethiopia, PHD dissertations submitted school of graduate studies AAU, pp.65. 
Harp, J.A., Woodmansee, D.B., and Moon, H.W. (1990). Resistance of calves to Cryptosporidium parvum: effects of age and previous exposure. Infect Immun, 58: 2237-2240.

Helmy, Y.A., Kruecken, J., Noeckler, K., von Samson-Himmelstjerna, G., and Zessin, K.H. (2013). Molecular epidemiology of Cryptosporidium in livestock animals and humans in the Ismailia province of Egypt. Vet Parasitol,193: 15-24.

Hijjawi, N. S., Meloni, B. P., Ryan, U. M., Olson, M. E., and Thompson, R. C. A. (2002). Successful in vitro cultivation of Cryptosporidium andersoni: evidence for the existence of novel extracellular stages in the life cycle and implications for the classification of Cryptosporidium. International Journal for Parasitology, 32(14): 1719-1726.

Hijjawi, N.S., B.P. Meloni, M. Ng'anzo, U.M. Ryan, M.E. Olson,P.T. Cox,P.T. Monis, and R.C.A.Thompson, (2004). Complete developmentof Cryptosporidium parvum in host cell-free culture. International Journal for Parasitology, 34: pp. 769-777

Huetink, R.E., van der Giessen, J.W., Noordhuizen, J.P., and Ploeger, H.W. (2001). Epidemiology of Cryptosporidium spp. and Giardia duodenalis on a dairy farm. Vet. Parasitol, 102: 53-67.

Hunter, P.R., and Thompson, R.C.A. (2005). The zoonotic transmission of Giardia and Cryptosporidium. Int. J. Parasitol, 35: 1181-1190.

Iqbal, J., Hira, P.R., Ali, F. and Philip, R. (2001). Cryptosporidiosis in Kuwaiti children, seasonality and endemicity. J.Clin. micribiol.Infect.,7: 261-266.

Jarvie, B.D. Trotz-Williams, L.A., McKnight, D.R., Leslie, K.E., Wallace, M.M., Todd, C.G., Sharpe, P.H., and Peregrine, A.S. (2005). Effect of halofuginone lactate on the occurrence of Cryptosporidium parvum and growth of neonatal dairy calves. J Dairy Sci, 88: 1801-1806.

Jenkins, M.C. (2001): Advances and prospects for subunit vaccines against protozoa of veterinary importance. Vet. Parasitol, 101: 291-310.

Jirku, M., Valigurova, A., Koudela, B., Krizek, J., Modry, D., and Slapeta, J. (2008). New species of Cryptosporidium Tyzzer, 1907 (Apicomplexa) from amphibian host: morphology, biology and phylogeny. Folia Parasitol (Praha), 55: 81-94.

Joachim, A., Krull, T., Schwarzkopf, J., and Daugschies, A. (2003): Prevalence and control of bovine cryptosporidiosis in German dairy herds. Vet. Parasitol, 112: 277-288.

Kaske, M., Smolka, K., and Andresen, U. (2008). Neonatal diarrhea in the calf - Etiology and path physiology. Der Praktische Tierarzt, 89: 852-859.

Khin, L., (2007). Prevalence of cryptosporidium, giardia and other gastrointestinal parasites in dairy calves in mandalay, Myanmar UNIVERSITY, Berlin, pp. 98.

Kvac, M., Kestranova, M., Pinkova, M., Kvetonova, D., Kalinova, J., Wagnerova, P., Kotkova, M., Vitovec, J., Ditrich, O., McEvoy, J., Stenger, B., and Sak, B. (2013). Cryptosporidium scrofarum n. sp (Apicomplexa: Cryptosporidiidae) in domestic pigs (Sus scrofa). Veterinary Parasitology, 191: 218-227.

Kvac, M., Kouba, M., and Vitovec, J. (2006). Age-related and housing-dependence of Cryptosporidium infection of calves from dairy and beef herds in South Bohemia, Czech Republic. Veterinary Parasitology, 137: 202-209.

Kvac, M., Nemejc, K., Kestranova, M., Kvetonova, D., Wagnerova, P., Kotkova, M., Rost, M., Samkova, E., McEvoy, J., and Sak, B. (2014). Age related susceptibility of pigs to Cryptosporidium scrofarum infection. Veterinary Parasitology, 202: 330-334.

Learmonth, J.J., Ionas, G., Ebbett, K.A. and Kwan, E.S. (2004). Genetic characterization and transmission cycles of Cryptosporidium species isolated from humans in New Zealand. Appl Environ Microbiol, 70: 3973-3978.

Leav, B.A., M. Mackay, and H.D. Ward. (2003). Cryptosporidium species: new insights and old challenges. Clin. Infect. Dis., 36: pp. 903-908.

Lebbad, M., Beser, J., Insulander, M., Karlsson, L., Mattsson, J.G., Svenungsson, B., and Axen, C. (2013). Unusual cryptosporidiosis cases in Swedish patients: extended molecular characterization of Cryptosporidium viatorum and Cryptosporidiumchipmunk genotype I. Parasitol, 140: 1735-1740.

Lefay D., Naciri, M., Poirier, P., and Chermette, R. (2001). Efficacy of halofuginon lactate in the prevention of cryptosporidiosis in suckling calves. Vet. Rec.,148: 108-112.

Lendner, M., Etzold, M., and Daugschies, A. (2011). Cryptosporidiosis-an update. Berl Munch Tierarztl Wochenschr, 124: 473-484.

Lindsay, D.S., Upton, S.J., Owens, D.S., Morgan, U.M., Mead, J.R., and Blagburn, B.L. (2000).Cryptosporidium andersoni (Apicomplexa: Cryptosporiidae) from cattle, Bostaurus. J. Eukaryot. Microbiol, 47: 91-95. 
Lorenz, I., Fagan, J. and More, S.J. (2011). Calf health from birth to weaning. II.Management of diarrhoea in pre-weaned calves. Ir. Vet. J., 64: 9.

Mahdi, N.K., and N.H. Ali, (2002). Cryptosporidiosis among animal handlers and their livestock in Basrah, Iraq. East Afr. Med. J., 79: 550-553.

Manabe, Y.C., Clark, D.P., Moore, R.D., Lumadue, J.A., Dahlman, H.R., Belitsos, P.C., Chaisson, R.E., and Sears, C.L. (1998). Cryptosporidiosis in patients with AIDS: correlates of disease and survival. Clin. Infect. Dis., 27: 536-542.

McDonald, V. (2000). Host cell-mediated responses to infection with Cryptosporidium. Parasite Immunol, 22 : pp. 597-604.

McLauchlin, J., Amar, C., Pedraza-Diaz, S. and Nichols, G.L. (2000). Molecular epidemiological analysis of Cryptosporidium spp. in the United Kingdom: results of genotyping Cryptosporidium spp. in 1,705 faecal samples from humans and 105 faecal samples from livestock animals. J. Clin. Microbiol, 38: 3984-3990.

McLauchlin, J., Pedraza-Diaz, S., Amar-Hoetzeneder, C., and Nichols, G.L. (1999). Genetic characterization of Cryptosporidium strains from 218 patients with diarrhea diagnosed as having sporadic cryptosporidiosis. $J$. Clin. Microbiol, 37: 3153-3158.

Megremis, S., Segkos, N., Daskalaki, M., Tzortzakakis, E., Paspatis, G., Zois, E., and Sfakianaki, E. (2004). Gallbladder cryptosporidiosis in a patients with acquired immunodeficiency syndrome: sonographic evaluation of the disease's course. J. Ultrasound. Med, 23: 137-140.

Moore, D.A., Atwill, E.R., Kirk, J.H., Brahmbhatt, D., Herrera Alonso, L., Hou, L., Singer, M.D., and Miller, T.D. (2003). Prophylactic use of decoquinate for infections with Cryptosporidium parvum in experimentally challenged neonatal calves. J Am Vet MedAssoc, 15: 839-845.

Morgan-Ryan, U.M., Fall, A., Ward, L.A., Hijjawi, N., Sulaiman, I., Fayer, R.Thompson, R.C., Olson, M., Lal, A., and Xiao, L. (2002). Cryptosporidiumhominis n. sp. (Apicomplexa: Cryptosporidiidae) from Homo sapiens. J Eukaryot. Microbiol, 49: 433-440.

Mosier, D.A., and Oberst, R.D. (2000). Cryptosporidiosis. A global challenge.Ann N Y Acad Sci, 916: 102-111.

Ng-Hublin, J.S., Combs, B., MacKenzie, B., and Ryan, U. (2013). Human cryptosporidiosis diagnosed in Western Australia: a mixed infection with Cryptosporidium meleagridis, the Cryptosporidium mink genotype, and an unknown Cryptosporidium species. J Clin. Microbiol, 51: 2463-2465.

Nguyen, S. T., Nguyen, D. T., Quyet Le, D., Le Hua, L. N., Nguyen, T. V., Honma, H.,and Nakai ,Y. (2007). Prevalence and first genetic identification of Cryptosporidium spp. In cattle in central Viet Nam. Veterinary Parasitology, 150: 357-361.

Nydam, D.V., Wade, S.E., Schaaf, S.L., and Mohammed, H.O. (2001). Number of Cryptosporidium parvum oocysts or Giardia spp cysts shed by dairy calves after natural infection. Am. J Vet Res, 62: 1612-1615.

Okhuysen, P.C., Chappell, C.L., Crabb, J.H., Sterling, C.R., and DuPont, H.L. (1999). Virulence of three distinct Cryptosporidium parvum isolates for healthy adults. J Infect Dis, 180:1275-1281.

Olson, M.E., O’Handley, R.M., Ralston, B.J., McAllister, T.A., and Thompson, R.C.A. (2004). Update on Cryotosporidium and Giardia infections in cattle. Trends Parasitol, 20: 185-191.

Papini, R., and Cardini, G. (2006). Evaluation of a rapid Cryptosporidium/Giardiaimmunochromatographic test for diagnosis of giardiasis in dogs. Revue Méd. Vét ,157: 490-493.

Petry, F. (2000). Laboratory diagnosis of C. parvum infection. In Cryptosporidiosis and Pozio, E. and Morales, M.A. (2005). The impact of HIV-protease inhibitors on opportunistic parasites. Trends Parasitol, 21: 5863.

Preiser, G., Preiser, L., and Madeo, L. (2003). An outbreak of cryptosporidiosis among veterinary science students who work with calves. J. Am. Coll. Health, 51: pp.213- 215.

Putignani, L., and Menichella, D. (2010). Global distribution, public health and clinical impact of the protozoan pathogen cryptosporidium. Interdiscip Perspect Infect Dis 2010 doi:10.1155/2010/753512.

Radostits, O.M., C.C. Gay, K.W. Hinchcliff and P.D. Constable, (2006). Diseases associated with protozoa. 10 edition, In: Veterinary Medicine: A Textbook of Diseases of cattle, horses, sheep, pigs and goats. Saunders Elsevier, pp: 1483-1540.

Radostits, O.M., Gay, C.C.Blood, D.C.A. and Hinchcliff, K.W. (2006). Veterinary medicine W.B sounder 9ed,:1310-1314.

Ralston, B.J., McAllister, T.A., and Olson, M.E. (2003). Prevalence and infection pattern of naturally acquired giardiosis and cryptosporidiosis in range beef calves and their dams. Vet. Parasitol, 114: 113-122.

Ramirez, N.E., L.A. Ward, and S. Sreevatan, (2004). A review of the biology and epidemiology of cryptosporidiosis in humans and animals. Microbes and Infection, 6: pp. 773-785. 
Riggs, M.W. (2002). Recent advances in cryptosporidiosis: the immune response. Microbes. Infect, 4: 10671080.

Rimhanen-Finne, R. (2006). Cryptosporidium and Giardia: detection in environmental and faecal samples. Finland: University of Helsinki, Faculty of Veterinary Medicine, Dissertation.

Ryan, U., and Xiao L. (2003). Proposals for a revised taxonomy of Cryptosporidium parasites. In:Latham SM, Smith HV, Wastling JM (eds). Proceedings Workshop on the application of genetic fingerprinting for the monitoring of Cryptosporidium in humans, animals and the environment., Boulder, USA, Foundation of Water Research, Marlow, UK, Pp. 13-32.

Ryan, U.M., Bath, C., Robertson, I., Read, C., Elliot, A., McInnes, L., Traub, R., and Besier, B. (2005). Sheep may not be an important zoonotic reservoir for Cryptosporidium and Giardia parasites. Appl. Environ. Microbiol, 71: 4992- 4997.

Ryan, U.M., Xiao, L., Read, C., Sulaiman, I.M., Monis, P., Lal, A.A., Fayer, R., and Pavlasek, I. (2003). A redescription of Cryptosporidium galli Pavlasek,1999 (Apicomplexa: Cryptosporidiidae) from birds. $J$ Parasitol, 89: 809-813.

Santı'n, M., Trout, J.M., Xiao, L., Zhou, L., Greiner, E.,and Fayer, R. (2004): Prevalence and age related variation of Cryptosporidium species and genotypes in dairy calves. Vet. Parasitol, 122: 103-117.

Sarah,T. (2016). Cryptosporidiosis in farm livestock. PhD thesis, University of Glasgow, pp. 205.

Shahiduzzaman, M., and Daugschies, A. (2012). Therapy and prevention of cryptosporidiosis in animals. Vet Parasitol188: 203-214.

Silverlas, C., Mattsson, J.G., Insulander, M., and Lebbad, M. (2012). Zoonotic transmission of Cryptosporidium meleagridis on an organic Swedish farm. Int J Parasitol, 42: 963-967.

Slapeta, J. (2007). Cryptosporidium species found in cattle: a proposal for a new species. Tren.Parasitol, $\quad \mathbf{2 2 :}$ 469-474.

Slapeta, J. (2013). Cryptosporidiosis and Cryptosporidium species in animals and humans: a thirty colour rainbow? Int. J. Parasitol, 43: 957-970.

Smith, H.V., Caccio, S.M., Cook, N., Nichols, R.A., and Tait, A. (2007). Cryptosporidium and Giardia as foodborne zoonoses. Vet Parasitol, 149: 29-40.

Smith, H.V., Nichols, R.A., Mallon, M., MacLeod, A., Tait, A., Reilly, W.J., Browning, L.M., Gray, D., Reid, S.W., and Wastling, J.M. (2005). Natural Cryptosporidium hominis infections in Scottish cattle. Veterinary Record, 156: 710-711.

Snelling, J.W. (2007). Cryptosporidiosis in developing countries. Journal of Infection in Developing Countrie,. 1(3):242-256.

Stantic-Pavlinic, M., Xiao, L., Glaberman, S., Lal, A.A., Orazen, T., Rataj-Verglez, A., Logar, J., and Berce, I. (2003). Cryptosporidiosis associated with animal contacts.

Strickland, G. T. (2000). Hunter's Tropical Medicine and emerging infectious diseases $8^{\text {th }}$ ed. Philadelphia: WB Saunders, pp. 134-198.

Strong, W.B., Gut, J., and Nelson, R.G. (2000). Cloning and sequence analysis of a highly polymorphic Cryptosporidium parvum gene encoding a 60- kilodalton glycoprotein and characterization of its 15 - and 45-kilodaltonzoite surface antigen products. Infect. Immun, 68: 4117-4134.

Suleiman, I., A., Lal. and L. Xiao, (2001). A population genetic study of the Cryptosporidium parvum human genotype parasites. J. Eukaryot. Microbial.,57: 245-275.

Suleiman, I.M., Xiao, L., and Lal, A.A., (1999). Evaluation of C. parvum genotyping techniques. Appl. Environ. Microbiol, 65: pp. 4431-4435.

Sunnotel, O., Lowery, C.J., Moore, J.E., Dooley, J.S., Xiao, L., Millar, B.C., Rooney, P.J., and Snelling, W.J. (2006). Cryptosporidium. Lett Appl Microbiol, 43: 7-16.

Teunis, P.F., Chappell, C.L., and Okhuysen, P.C. (2002). Cryptosporidium dose-respond studies: variation between hosts. Risk Anal, 22: 475-485.

Thompson, R.C.A., and Smith, A. (2011). Zoonotic enteric protozoa. Vet. Parasitol, 182: 70-78.

Thomson, S. (2016). Cryptosporidiosis in farm livestock. PhD thesis. University of Glasgow,pp. 206.

Trotz-Williams, L.A., Jarvie, B.D., Peregrine, A.S., Duffield, T.F., and Leslie, K.E. (2011). Efficacy of halofuginone lactate in the prevention of cryptosporidiosis in dairy calves. Vet Rec, 168: 509.

Tumova, E., Skrivan, M., Marounek, M., Pavlasek, I., and Ledvinka, Z. (2002). Performance and oocyst shedding in broiler chickens orally infected with Cryptosporidium baileyi andCryptosporidium meleagridis. Avian Dis 46: 203-207.

Tyzzer, E.E. (1910). An extracellular Coccidium, Cryptosporidium Muris (Gen. Et Sp. Nov.),of the gastric Glands of the Common Mouse. J Med Res, 23: 487- 510. 
Tzipori, S., Smith, M., Halpin, C., Angus, K.W., Sherwood, D., and Campbell, I. (1983). Experimental cryptosporidiosis in calves: clinical manifestations and pathological findings. Vet Rec, 112: 116-120.

Viu, M., Quilez, J., Sanchez-Acedo, C., Del, C.E., and Lopez-Bernad, F. (2000). Field trial on the therapeutic efficacy of paromomycin on natural Cryptosporidium parvum infections in lambs. Vet Parasitol, 90: 163170.

Wang, Y., Yang, W., Cama, V., Wang, L., Cabrera, L., Ortega, Y., Bern, C. Feng, Y., Gilman, R., and Xiao, L. (2014). Population genetics of Cryptosporidium meleagridis in humans and birds: evidence for crossspecie transmission. Int J Parasitol,44: 515-521.

Wien, Klin., Mahdi, N.K. and Ali, N.H., (2002). Cryptosporidiosis among animal handlers and their livestock in Basrah, Iraq. East Afr. Med. J, 79: 550-553.

Xiao, L., fayer, R., Ryan, U. and Upton S.J., (2004). Cryptosporidium taxonomy: recent advances and implications for public health. Clin. Microbiol. Rev., 17: 72-97.

Yang, R., Jacobson, C., Gardner, G., Carmichael, I., Campbell, A.J., Ng-Hublin, J., and Ryan, U. (2014). Longitudinal prevalence, oocyst shedding and molecular characterisation of Cryptosporidium species in sheep across four states in Australia. Vet Parasitol, 200: 50-58.

Yang,Y.L., Buck, G.A. and WidmeR, G. (2010). Cell sorting-assisted microarray profiling of host cell response to Cryptosporidium parvum infection. Infect. Immun, 78: 1040-1048.

Yosra, A., (2014).Epidemiological investigations on the public health significance of Cryptosporidium parasites in livestock and people in the Ismailia Canal Zone of Egypt, pp. 245.

Zambriski, J.A., Nydam, D.V., Bowman, D.D., Bellosa, M.L., Burton, A.J., Linden, T.C., Liotta, J.L., Ollivett, T.L., Tondello-Martins, L., and Mohammed, H.O. (2013). Description of fecal shedding of Cryptosporidium parvum oocysts in experimentally challenged dairy calves. Parasitology Research,112: 1247-1254.

Zone of Egypt, PhD Thesis, der Freien Universität Berlin, pp. 80.

Citation: A. Mohammed et al., "Cryptosporidium and Its Public Health Importance: Review ", International Journal of Research studies in Microbiology and Biotechnology, vol. 3, no. 4, p. 12-31, 2017. http://dx.doi.org/10.20431/2454-9428.0304004

Copyright: (C) 2017 Authors. This is an open-access article distributed under the terms of the Creative Commons Attribution License, which permits unrestricted use, distribution, and reproduction in any medium, provided the original author and source are credited. 